\title{
DETERMINATION OF THE VIBRATION CHARACTERISTICS OF BRIDGE IN DYNAMIC DIAGNOSIS
}

\author{
NGUYEN CAO MENH AND PhaM XUAN KHANG \\ Institute of Mechanics
}

\begin{abstract}
On the basis of dynamic diagnosis equipment VDIK-1-10 of Russia and finite element method (FEM), the procedures for finding the exciting places and measurement points of vibration are presented. They give us clear information of diagnostic parameters. After data processing we can determine the dynamic characteristics parameters of the bridge. The parameters obtained are used to updating modeling parameters of FEM and therefore the technical state of the bridge could be estimated. An example for investigation of prestressed concrete bridge with $33 \mathrm{~m}$ span and $10 \mathrm{~m}$ width is illustrated.
\end{abstract}

\section{Introduction}

Dynamic diagnosis is the close combination of computation and measurement of dynamic responses of mechanical system such as structures and bridges. After data processing one can get important measurement parameters for updating the modeling parameters of FEM, estimating technical state of the systems and, finaliy, to detect their damages and defects. It is difficult to reach the latest purpose quickly but the results have to be improved gradually.

The dynamical monitoring and diagnosis method for bridges is now developing and improving due to the progress of informatics and measurement equipments $[1,2]$. New equipment set VDIK-1-10 is made by Russia for this purpose. As we know that the FEM contains a large number of degrees of freedom and only a small number of data can be measured in the limited frequency range. Therefore, there is a need of determination of location of measuring points to assure that the necessary data is collected. On the other hand, it is necessary to find out some main parameters for comparison with computation results.

\section{The VDIK-1-10 Equipment}

\subsection{The VDIK-1-10 equipment}

This equipment is used for dynamic diagnosis of bridge. It has two part: 
the vibrator SV-5-150 and laboratory. The vibrator is on the truck (URAL or KAMAZ) to make the standard excitation. These excited forces are harmonic with frequencies from 0.5 to $50 \mathrm{~Hz}$, amplitudes from 0 to 30 ton. The process of exciting, measuring and result writing is controlled by a PC on laboratory. There are 8 measurement sensors, each of them can measure in 2 directions. The measurement process is synchronous with the excited process.

\subsection{The softwares of VDIK-1-10 equipment}

The software of VDIK-1-10 equipment contains 2 types:

- The software control the equipment and analyzes the measurement data concludes

The software controls the vibrator and writes the data

The software analyzes the data by FFT method and display

The software animates the vibration of bridge.

- The software analyzes the structure by FE method (COSMOS/M).

Using VDIK-1-10 equipment we obtain the vibration characteristics of the bridge such as the natural frequencies, mode shapes (if measuring in suitable places). In order to use the equipment set efficiently it is necessary to apply and modify the methodsof data processing and FEM.

\section{The FEM Model of Structure}

\subsection{The FEM Model}

When establish the FEM model of structure, we must base on the principles:

- The FEM model must appropriate with actual structure on stiffness, mass in all its elements. FEM model must also describe rather exactly the mechanical properties of the structure.

- The FEM model is easy to describe the defects in the structure.

For illustration we establish a FEM model for the prestressed concrete bridge with $33 \mathrm{~m}$ span, $10 \mathrm{~m}$ width.

3.2 Scheme of bridge structure (dimensions assign by centimeters)

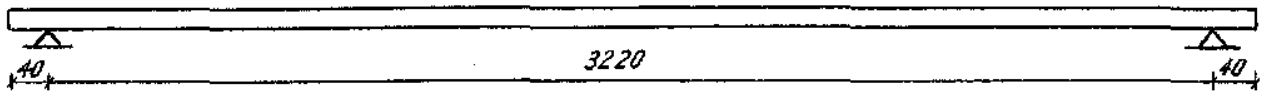

$1 / 2$ section of the bridge ends

$1 / 2$ section at midspan 


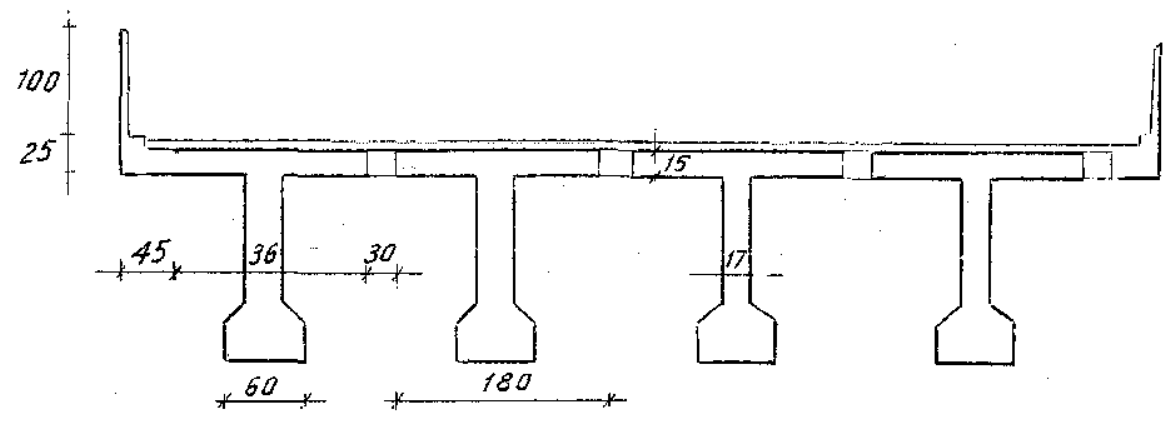

The arrange of prestressed cables

At the ends of beam

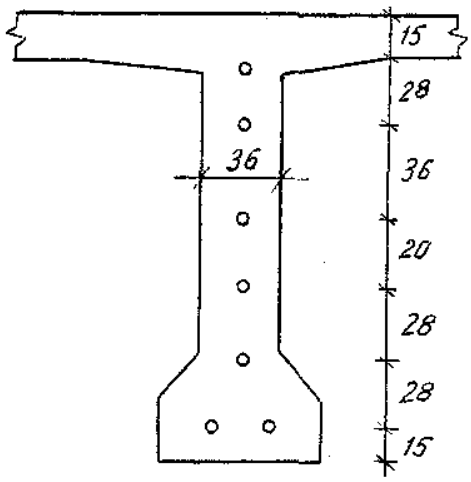

At midspan

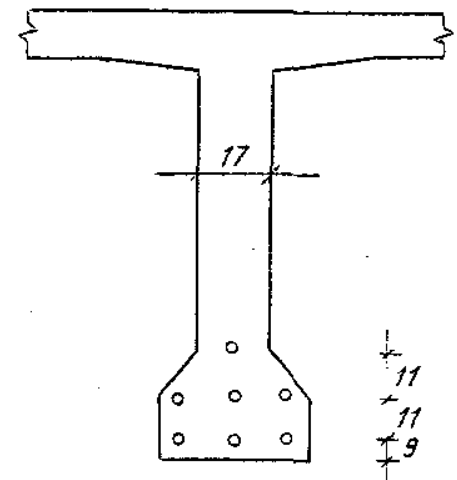

Fig. 1. Scheme of bridge structure

\subsection{FEM model of bridge}

The beam contains: web, flange and concrete cross brace. There are elements for which 2 sizes are much more greater than the third size. So that, we consider them as a shell. Another elements contain: parapest, prestressed reinforced are bars. Bridge surface (asphalt) have a little thickness (about $10 \mathrm{~cm}$ ) and small stiffness, so only their masses are added into the flange and cross brace of beam. The FEM model of bridge has 980 nodes, contains 388 frame elements, 912 shell elements. The boundary conditions are fixed bearings in an end of beams, and moving bearing in other end.

By this way, the FEM model describes basical properties of the bridge and its behaviour under load action.

\subsection{Calculation Results}

The program SAP-90 is used for calculation of dynamical chacateristics of the bridge with $33 \mathrm{~m}$ span and $10 \mathrm{~m}$ with. First eight mode shape of vibration of the bridge are obtained and shown in Fig. 2. The measurement results of the first natural frequency of undamage bridges are follows: 

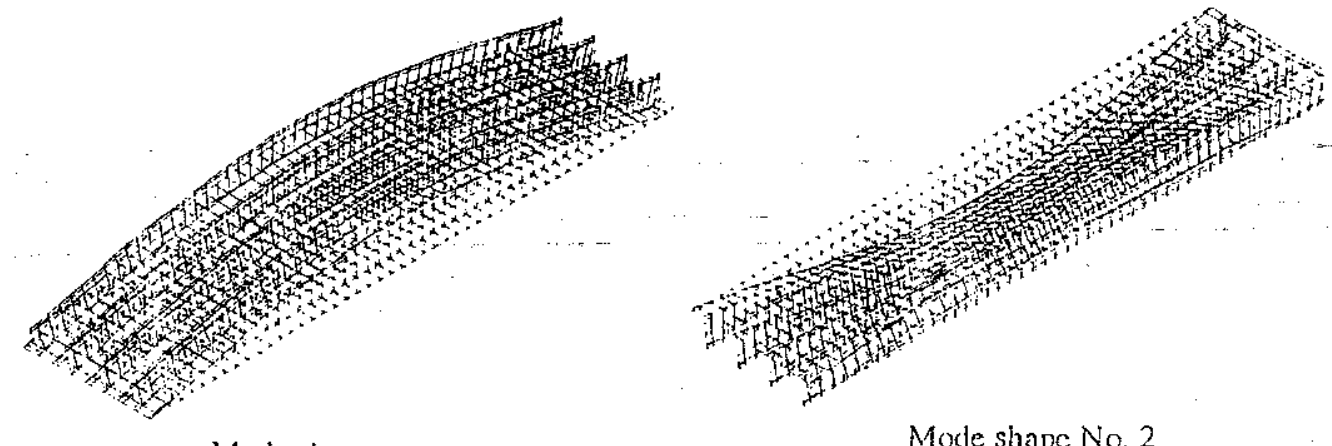

Mode shape No. 1

Mode shape No. 2

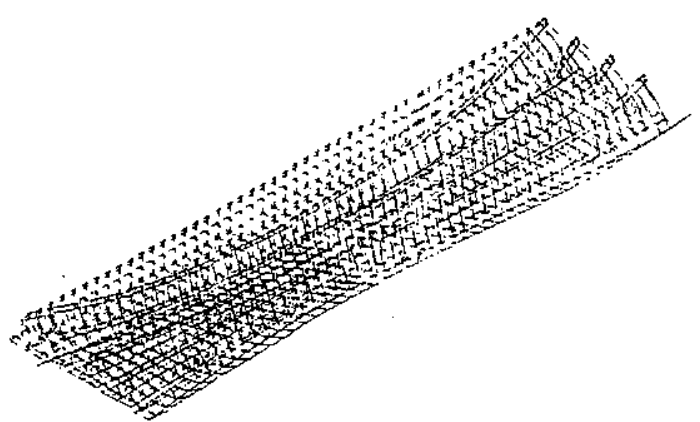

Mode shape No. 3

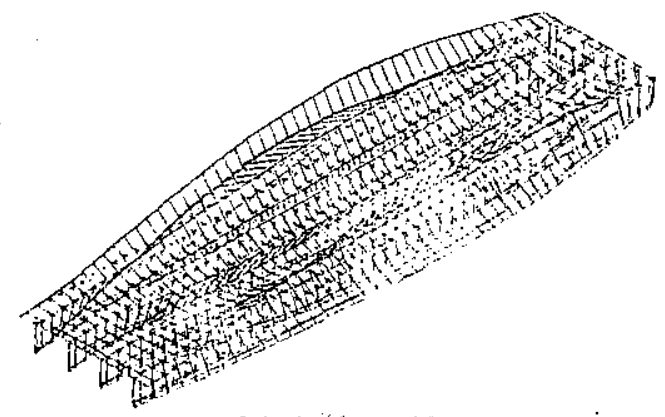

Mode shape No. 4

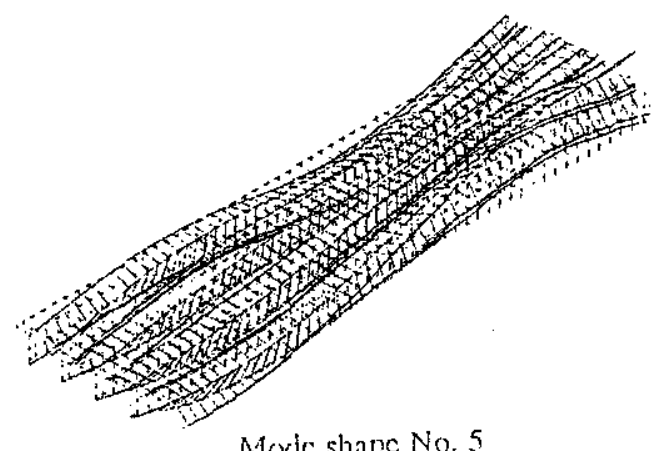

Moxic shape No. 5
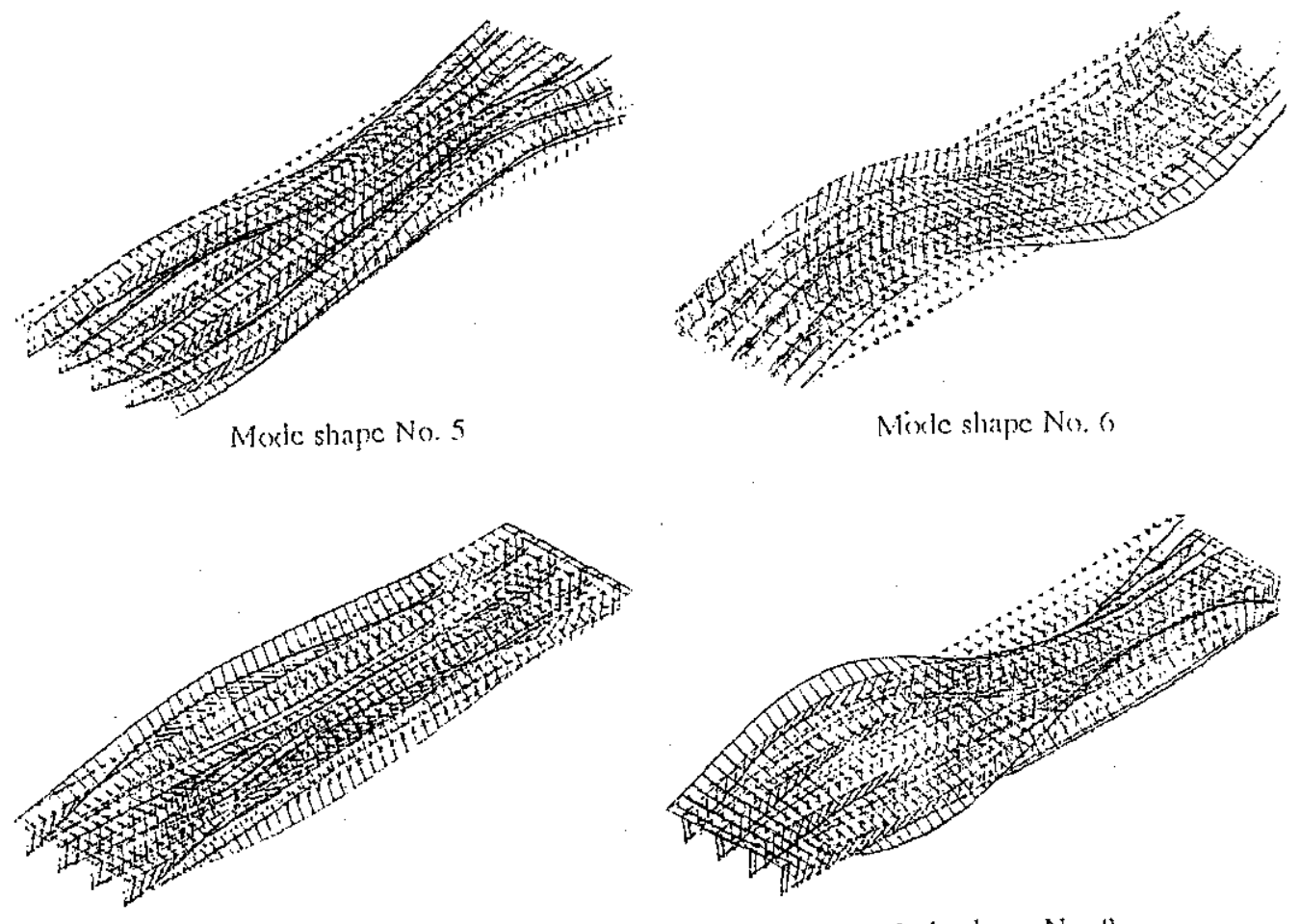

Mode sharp No.7

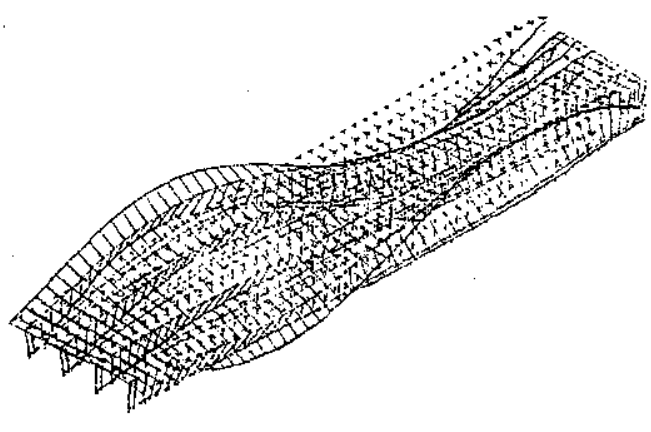

Mole shipe No. 8

Fig. 2. Mode shapes calculated in FEM model 
- Yen Bai bridge: $3.25 \mathrm{~Hz}$

- Song Hieu bridge (Nghe An province): $3.3 \mathrm{~Hz}$

The corresponding result is calculated by FEM: $3.14 \mathrm{~Hz}$

These results show that our FEM model and practical problem are suitable and the model could be used for diagnostic purposes.

\section{Distribution of measurement points and data processing}

\subsection{Measurement points and exciter positions}

It is necessary to find out the places for putting vibration measurement sensor and vibrator, where it is easier to process signal records and get important dynamical characteristics of the bridge under dynamic load, for example, natural frequencies, mode shapes and corresponding amplitudes.

The calculation by FEM for above prestressed concrete bridge of $33 \mathrm{~m}$ span, $10 \mathrm{~m}$ width shows that mode shapes 7,8 are complicated ones, requiring many sensor for identification, that is out of capacity of the equipment set. Therefore, the low frequencies $1,2,3,4,5,6$ and corresponding mode shapes will be considered and compared in measurements and calculations.

According to many authors $([1,2])$, the natural frequencies of the bridge should be studied in the range from 1 to $15 \mathrm{~Hz}$. The frequency band could be reduced depending on the bridge span and in our case it is about from 2 to $12 \mathrm{~Hz}$.

For 1st, 2rd mode shapes, it is obvious that the best measurement positions are in the midspan with 2 measurement at two ledge beam and corresponding point at the bearings or 4 midspan measurement points. Measurement points at the bearings have the role of obtaining vibration of the bearings, on which comparisons of span's vibration are based. The vibrator is located at the geometrically symmetric center of the structure (in the midlle of bridge). The other mode shapes could be done by a similar way, for example, for 6 th mode shape the best measurement position is at $1 / 4$ or $3 / 4$ span and the vibrator position is at $1 / 4$ or $3 / 4$ span section along central line of the bridge.

\subsection{Measurement dynamic characteristics}

After determination of measurement and exciting positions it is possible to use effectively the VDIK-1-10 equipment set. Changing the frequency of exciting load the equipment indicates the natural frequencies with damping and corresponding amplitudes by suddenly increasing of amplitude. The diagram of spectral density function shows more clearly the natural frequency. The mode shapes of the 
structure can be obtained by the results of several measurement points.

Notice that the calculation of bridge by FEM gives us the natural frequencies without damping. Therefore, in order to compare frequencies calculated and measured and deduce usefull conclusions for diagnosis of damages and defects of bridge, it is necessary to process measurement data and get rid of damping from measured frequencies.

\subsection{Define damping}

Using FEM for calculating a structure, it is possible to obtain the following equation system

$$
\mathbf{M U}+\mathbf{C} \dot{\mathbf{U}}+\mathbf{K} \mathbf{U}=\mathbf{Q}(t)
$$

where

$\mathbf{M}, \mathbf{C}, \mathbf{K}-n \times n$ matrices of mass, damping coefficient and stiffness, respectively

$\mathbf{U}, \mathbf{Q}: n$-vectors of nodal displacements and exciting forces.

Thus, the dynamical analysis problem of structures leads to solve the equation system (1). For this purpose, there are several approarches, from which the so called method of superposition is most widely used. The solution of the eigenvalue problem

$$
\left(\mathbf{K}-\omega^{2} \cdot \mathbf{M}\right) \phi=0
$$

gives $n$ natural modes of vibration including natural frequencies $\omega_{1}, \omega_{2}, \ldots, \omega_{n}$ and corresponding mode shapes $\phi(j)=\left\{\phi_{1}(j), \phi_{2}(j), \ldots, \phi_{n}(j)\right\}, j=1, \ldots, n$.

The natural frequencies and mode shapes have the following properties:

- Mode shapes are perpendicular with respect to stiffness matrix $\mathbf{K}$ and mass matrix $\mathbf{M}$.

$$
\begin{aligned}
\phi^{T}(i) \cdot \mathbf{M} \cdot \phi(j) & = \begin{cases}0 & j \neq i \\
m_{i} & j=1\end{cases} \\
\phi^{T}(i) \cdot \mathbf{K} \cdot \phi(j) & = \begin{cases}0 & j \neq i \\
k_{i} & j=i\end{cases}
\end{aligned}
$$

- The natural frequency $\omega_{j}$ can be determined by

$$
\omega_{j}=\sqrt{\frac{k_{j}}{m_{j}}}, \quad j=1, \ldots, n
$$

The damping of structure is considered due to the energy consuming during every period, and thus depends on the natural frequency. Suppose that the 
lamping matrix has the following property

$$
\phi^{T}(i) \cdot \mathbf{C} \cdot \phi(j)= \begin{cases}0 & j \neq i \\ c_{i} & j=i\end{cases}
$$

Denote damping coefficient in $i$ th natural vibration by $h_{i}$ which is determined sy the formula

$$
h_{i}=\frac{c_{i}}{2 \sqrt{k_{i} \cdot m_{i}}} \quad i=1, \ldots, n
$$

For SAP-90 the mass $m_{i}$ corresponding $\omega_{i}$ is normalized, therefore $m_{i}=1$.

The general solution of (4.1) can by written as:

$$
\mathbf{U}(t)=\boldsymbol{\Phi} \cdot \boldsymbol{\xi}(t)
$$

where $\boldsymbol{\Phi}=(\phi(1), \phi(2), \ldots, \phi(n))$ is the mode shape matrix, and

$\phi(j)=\left\{\phi_{1}(j), \phi_{2}(j), \ldots, \phi_{n}(j)\right\}^{T}$ is a eigenvector with respect to $\omega_{j}$.

$\xi(t)=\left\{\xi_{1}(t), \xi_{2}(t), \ldots, \xi_{n}(t)\right\}$ is a normal coordinate vector.

Substituting (4.8) into (4.1) and taking into account (4.3)-(4.6) we have

$$
\begin{gathered}
\mathbf{M} \cdot \boldsymbol{\Phi} \cdot \ddot{\boldsymbol{\xi}}+\mathbf{C} \cdot \mathbf{\Phi} \cdot \dot{\boldsymbol{\xi}}=\mathbf{Q}(t) \\
\ddot{\xi}_{j}(t)+c_{j} \dot{\xi}_{j}(t)+k_{j} \xi_{j}(t)=\Phi(j) \cdot P(t), \quad j=1, \ldots, n
\end{gathered}
$$

Denoting $k_{j}=\omega_{j}^{2}$ and $2 \cdot h_{j}=\frac{c_{j}}{\omega_{j}}$, we have

$$
\ddot{\xi}_{j}(t)+2 h_{j} \omega_{j} \dot{\xi}_{j}(t)+\omega_{j}^{2} \xi_{j}(t)=\Phi(j) \cdot Q(t)=\sum_{i=1}^{n} \Phi_{i}(j) \cdot Q(t)
$$

The index $i$ indicates the nodal point. Therefore, if we have exciting force only at the node $k$, then the sume in the left side has simple form:

$$
\Phi(j) \cdot Q(t)=\Phi_{k}(j) \cdot Q_{k}(t)
$$

where the value $\Phi_{k}(j)$ is calculated by SAP-90 at nodal point $k$ for natural frequency $\omega_{j}$ and $Q_{k}(t)$ is exciting force at nodal point $k$. In this case

$$
Q_{k}(t)=A_{k} \cos \omega t
$$


and the equation (4.11) is

$$
\ddot{\xi}_{j}(t)+2 h_{j} \omega_{j} \dot{\xi}_{j}(t)+\omega_{j} \xi_{j}(t)=\Phi_{k}(j) \cdot A_{k} \cdot \cos \omega t
$$

The stationary solution of the equation (4.14) is

$$
\begin{gathered}
\xi_{j}(t)=X_{j} \cos (\omega t+\varphi) \\
X_{j}=\frac{\Phi_{k}(j) \cdot A_{k}}{\left[\left(\omega_{j}^{2}-\omega^{2}\right)^{2}+2\left(h_{j} \cdot \omega \cdot \omega_{j}\right)^{2}\right]^{1 / 2}} \\
\varphi=\tan ^{-1}\left(\frac{c_{j} \omega}{\left.\omega_{j}^{2}-\omega^{2}\right)}\right)
\end{gathered}
$$

The frequency of vibrator can be changed until the amplitude reaches maximal value, that means

$$
\omega^{2}=\omega_{j}^{2}-h_{j}^{2}
$$

The formula (4.16) becomes

$$
X_{j}^{2}=\frac{\Phi_{k}^{2}(j) \cdot A_{k}^{2}}{h_{j}^{4}+4 h_{j}^{2} \omega^{2}\left(\omega^{2}+h_{j}^{2}\right)}, \quad h_{j}^{4}\left(1+4 \omega^{2}\right)+4 h_{j}^{2} \omega^{4}=\frac{\Phi_{k}^{2}(j) \cdot A_{k}^{2}}{X_{j}^{2}} .
$$

Since in practice $h_{j}$ is usually small, then the term $h_{j}^{4}$ can be neglected and the equation (4.19) has the form

$$
2 h_{j} \omega^{2}=\frac{\Phi_{k}(j) A_{k}}{X_{j}}, \quad h_{j}=\frac{\Phi_{k}(j) A_{k}}{2 \omega^{2} X_{j}}
$$

where $\Phi_{k}(j)$ is calculated by SAP-90.

$A_{k}$ - amplitude of exciting force in point $k$.

$\omega$ - frequency, measured corresponding with maximal amplitude.

$X_{j}$ - amplitude, measured in point $k$.

From (4.18) we have $\omega_{j}^{2}=\omega^{2}+h_{j}^{2}$. So we can find the natural frequency without damping to compare with the one calculated in FEM model.

For illustration, we analyze the measurement data in Yen Bai Bridge in the first natural frequency: $A_{k}=30000, X_{j}=0.0005885, \omega=3.25, \Phi(j)=0.1889$.

By substituting into $(4.20)$ we have $h_{j}=0.1221 \Rightarrow \omega_{1}=3.248$ 


\section{Jonclusion}

By using VDIK-1-10 equipment with measurement-scheme calculated on FEM nodel of bridge, and analyzing the measurement data, we can determine the viration characteristics of the bridge for dynamic diagnosis.

This work is completed with financial support from the Council for Natural icience of Vietnam.

\section{References}

1. Nguyễn Cao Mệnh, Nguyễn Tiến Khiêm, Đỗ Sơn. Quy trình chẫn đoán kết cấu dàn khoan biển cố định bằng các đặc trưng động lực học. Tuyển tập công trình khoa học Hội nghị Cơ học Vật rắn biến dạng toàn quốc lần thứ 5 - Hà Nội 1996.

2. Mc Kenzi A. C., Macdonald F. J. Vibration as a useful tool bridge inspection.

3. Динамическая диагностика сооружений, Москва 1996

4. Friswell M. I. and Penny JE. T. The use of vibration data and model updating to detect damage

5. Редько С. Ф., Ущкалов В. Ф., Яковлев В. П. Идентификация механических систем определение динамических характеристик и параметров. Киев науковадумка 1985

6. Lê Văn Quý, Lều Thọ Trình. Động lực học công trình - Cơ học kết cấu. Nhà xuất bản Đại học và Trung học chuyên nghiệp - Hà Nội 1979.

Received July 15, 1998

\section{XÁC ĐỊNH CÁC ĐẶC TRƯNG DAO ĐộNG CƯA CẦU TRONG CHẨN ĐOÁN ĐộNG}

Dựa vào bộ thiết bị chẫn đoán động VDIK-1-10 cưa Liên bang Nga và phương pháp phần từ hữu hạn (PTHH), bài báo trình bày phương pháp xác định vị trí kích động và vị trí đo dao động sao cho nhận được nhiều thông tin của các tham số chẩn đoán. Sau khi xử lý số liệu, có thể xác định được các tham số đặc trưng động lực của cầu. Các tham số này được dùng để điều chỉnh tham số mô hình của phương pháp $\mathrm{PTHH}$ và có thể đánh giá trạng thái kỹ thuật của cầu. Để minh họa, trong bài này đã khảo sát cầu bê tông cốt thép ứng suất trước với nhịp $33 \mathrm{~m}$. và chiều rộng $10 \mathrm{~m}$. 